\title{
Intermediate depth earthquakes beneath the India-Tibet collision zone
}

\author{
Lupei Zhu and Donald V. Helmberger \\ Seismological Laboratory, California Institute of Technology, Pasadena
}

\begin{abstract}
We report on three intermediate depth earthquakes in the India-Tibet collision zone, two under the Himalayan Thrust Belt (HTB) and one beneath the Indus Zangbo suture. The $m_{b}$ magnitudes of these three events are from 4.3 to 4.9 , and are too small to be well located by conventional means. However, from modeling their broadband waveforms recorded at near-regional distances on a temporary PASSCAL array, we can confidently confine the sources to be below the crust, between 70 and $80 \mathrm{~km}$ deep. The existence of these intermediate depth earthquakes in this area suggests relatively low temperatures in the mantle lithosphere. The two events under the HTB display strikeslip mechanisms with some normal faulting component; this is quite different from the shallow thrust events typical of the same area. The principal $P$ and $T$ axes of all 3 fault plane solutions show roughly NS compression and EW extension, consistent with a regional stress field produced by the indenting of the India continent.
\end{abstract}

\section{Introduction}

Since the inception of the India-Eurasia collision at approximately $45 \mathrm{Ma}$, the India plate has indented northwards about $2000 \mathrm{~km}$, producing the highest continuous topography on earth, the Himalayas and the Tibetan plateau. In the past two decades, considerable efforts were made to investigate the crustal and uppermantle structure of this area in order to understand the collision mechanism and formation of the plateau (see Molnar, 1988 for a review).

Among various approaches, studying the source characteristics and depth distribution of earthquakes provides unique information about the mechanical properties and stress orientation of the lithosphere. There have been numerous results published based on the relocation and the source inversion of large events in the Tibetan Plateau and surrounding areas (Molnar and Chen, 1983; Baranowski et al., 1984; Ni and Barazangi, 1984; Molnar and Lyon-Caen, 1989; Zhao and Helmberger, 1991). These studies conclude that seismicity beneath the Tibetan plateau is shallow, restricted to the upper $20 \mathrm{~km}$ of the crust. Only three intermediate depth earthquakes (85-90 km deep) located in southern

\section{Copyright 1996 by the American Geophysical Union.}

Paper number 96GL00385

0094-8534/96/96GL-00385\$03.00
Tibet were reported (see Fig.1) (Chen et al., 1981; Molnar and Chen, 1983; Ekstrom, 1987; Chen, 1988). Due to the lack of seismic stations on the plateau, almost all of above studies used records from stations outside the plateau, usually at teleseismic distances, thus limiting the number of events that could be investigated. However, from 1991 to 1992, a PASSCAL experiment was conducted on the Tibetan Plateau with a deployment of 11 broadband stations. In this report, we present waveform modeling results of 3 events which show strong evidence of subcrustal focal depths. One of the events is located in the same area as two of previous intermediate depth events (Fig. 1), and the other two lie under the Himalayan Thrust Belt (HTB), where, to our knowledge, few intermediate depth events have been reported to date.

\section{Data and Results}

The stations occupied during the 1991-1992 Tibet PASSCAL experiment were equipped with STS-2 Streckeisen seismometers which have a flat velocity response between 0.008 to $50 \mathrm{~Hz}$. The details of the instrumen-

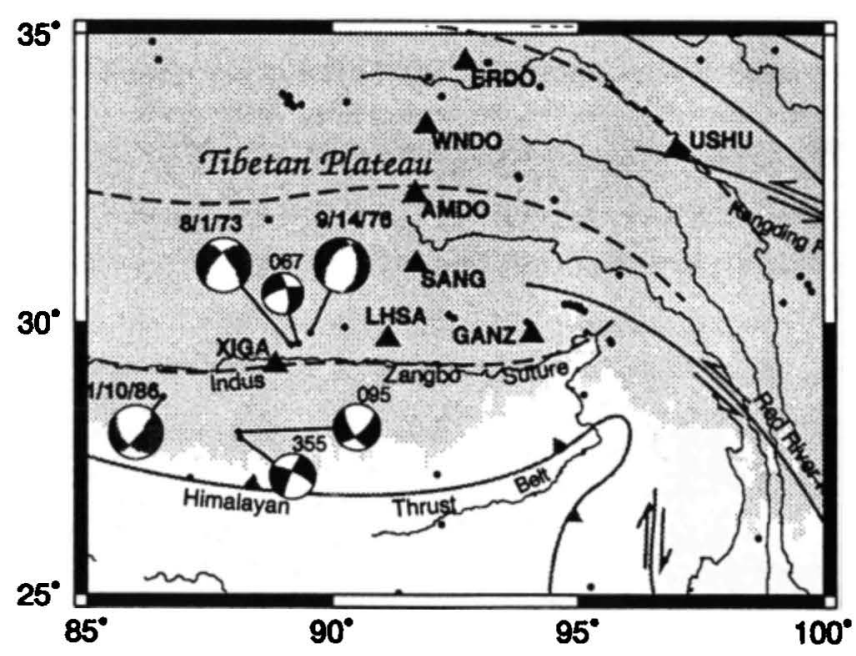

Figure 1. Map of southeastern Tibet showing major tectonic boundaries and the station locations (triangles) of the 1991-1992 Tibet PASSCAL experiment. Shading indicates elevation above $3 \mathbf{~ k m}$. Darkly shaded focal spheres are for subcrustal events analyzed in this study. Lightly shaded focal spheres are from Molnar and Chen (1983) and the Harvard CMT solution (for event on $1 / 10 / 86)$. All of them are located at intermediate depths. 
Table 1. Locations of the Events From PDE Catalog

\begin{tabular}{ccccc}
\hline Event & Date & Origin time & lat./lon./depth & $m_{b}$ \\
\hline 355 & $12-21-91$ & $19^{h} 52^{m} 45.5$ & $27.90 N / 88.14 E / 57$ & 4.9 \\
067 & $03-07-92$ & $22^{h} 41^{m} 50.8$ & $29.44 N / 89.37 E / 113$ & 4.3 \\
095 & $04-04-92$ & $17^{h} 43^{m} 20.7$ & $28.15 N / 87.98 E / 33$ & 4.9 \\
\hline
\end{tabular}

tation can be found in Owens et al. (1993). During its one-year deployment, about 50 earthquakes within the plateau were recorded by the array with good signal-tonoise ratios (Fig. 1). Randall et al. (1995) determined the focal depths and moment-tensors of 38 events in the north-central and southeastern part of the plateau by inverting long-period waveforms $(T>20 s)$. Their results agree with previous studies that have indicated shallow seismicity.

The PDE catalog locations and origin times of the three events investigated in this paper are listed in $\mathrm{Ta}$ ble 1. Events 355 and 095 are reported as crustal events and event 067 as subcrustal. A distinguishing character of all 3 events recorded on the array is their sharp direct $P$ and $S$ arrivals, even at large distances (Fig. 2). This feature suggests a subcrustal focal depth because the first arrivals beyond $320-350 \mathrm{~km}$ for crustal events in this region are head-waves with emergent onsets on broadband displacement records.

To test the sensitivity of waveforms to the focal depth, we have calculated the Green's functions for different source depths from $10 \mathrm{~km}$ to $90 \mathrm{~km}$, using a re-
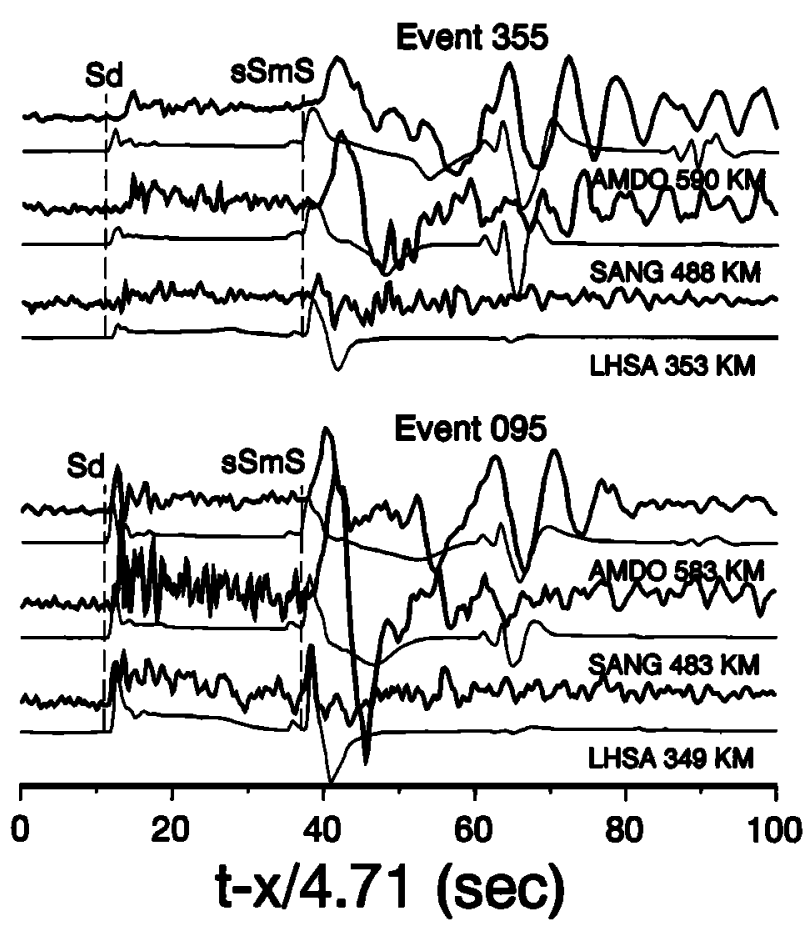

Figure 2. Examples of SH displacements of events 355 and 095 (thickened traces). Note the sharp onsets of $\mathrm{S}$ waves. The corresponding synthetics are computed using the 1-D model (Table 2) with source mechanism and depth obtained from waveform inversion.
Table 2. 1D Velocity Model of the Tibetan Plateau

\begin{tabular}{lccc}
\hline layer & Th. $(\mathrm{km})$ & $V_{p}(\mathrm{~km} / \mathrm{s})$ & $V_{s}(\mathrm{~km} / \mathrm{s})$ \\
\hline 1 & 4 & 4.70 & 2.70 \\
2 & 60 & 6.20 & 3.50 \\
3 & - & 8.14 & 4.70 \\
\hline
\end{tabular}

flectivity code developed by Saikia and Burdick (1991). The velocity model consists of two layers over a half space with the Moho at $64 \mathrm{~km}$ (Table 2). It is very similar to model M45 (Romanowicz, 1982) which has been proved reasonably good for modeling events on the Tibetan Plateau (Randall et. al, 1995). Fig. 3 shows the SH component of the Green's functions at a distance of $350 \mathrm{~km}$ for various source depths, along with the observed SH displacements for Events 355 and 095 recorded at the same distances. We focus on the SH displacement first because it is much simpler than P-SV displacement and has less dependence on source orientation. By comparing the waveforms for source depths of $60 \mathrm{~km}$ (above the Moho) and $70 \mathrm{~km}$ (below the Moho), one can see that the waveform shapes are quite diagnostic; the crustal synthetics predict a gently rising $S n$ phase whereas subcrustal events produce a sharp onset. Furthermore, the strong crustal phase $S d+S m S$ vanishes when the source is below the Moho. From the sharp $S$ arrivals and lack of $S d / S m S$ in the

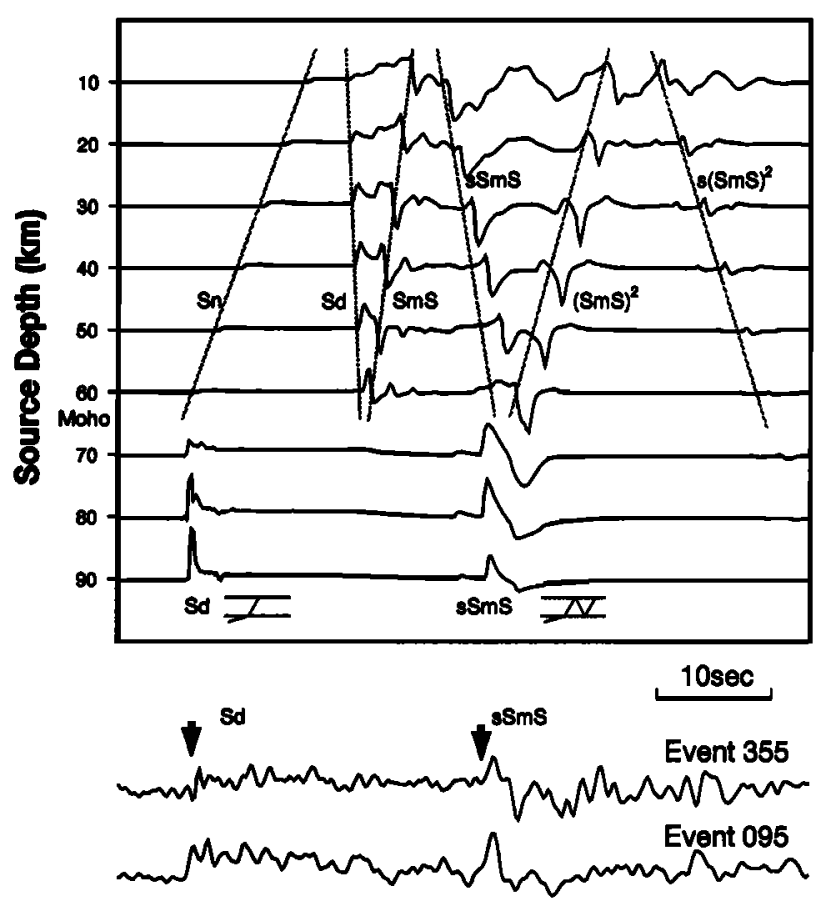

Figure 3. SH components of the Green's functions of a strike-slip source at different depths. The velocity model is given in Table 2. Distance range is $350 \mathrm{~km}$. Also shown in the figure are observed SH displacements of Events 355 and 095 recorded at station LHSA at the same distances. 

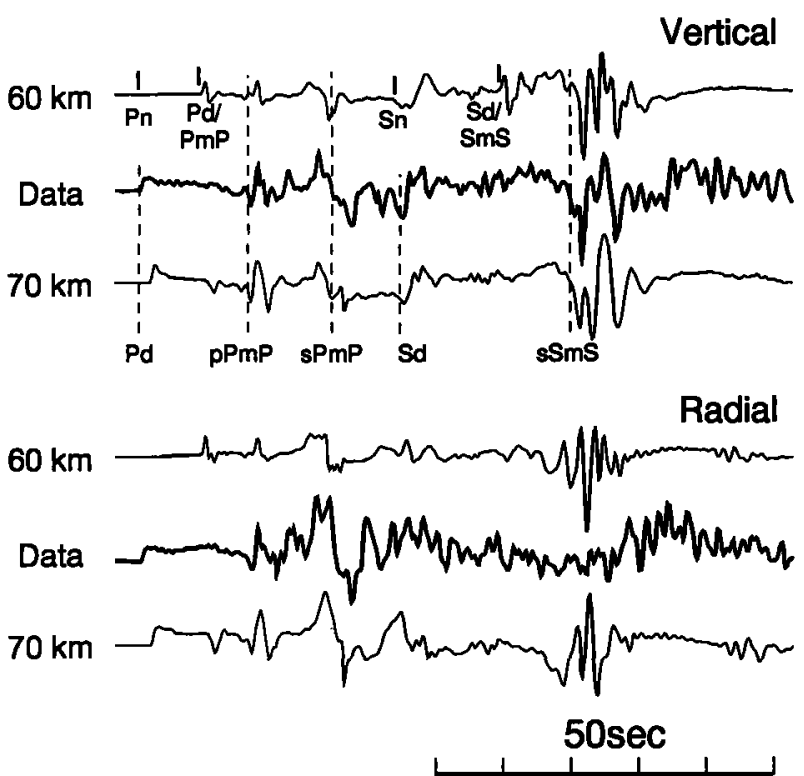

Figure 4. Comparison of vertical and radial displacements at station LHSA with synthetics from sources above $(60 \mathrm{~km})$ and below $(70 \mathrm{~km})$ the Moho. The synthetics are constructed using the source mechanisms obtained from the waveform inversion at corresponding depths.

observed waveforms, we conclude that Events 355 and 095 are subcrustal events. The synthetics for sources at 70,80 , and $90 \mathrm{~km}$ also show that for deeper source, the shape of first arrival is more impulsive. Accordingly, the step-like shape of first $S$ arrivals indicates that the two events are confined to the uppermost mantle.

Fig. 4 shows a comparison of vertical and radial displacements for Event 355 with synthetics generated from a source above the Moho $(60 \mathrm{~km})$ and below it $(70 \mathrm{~km})$. Source mechanisms obtained from inversion of the whole array data are used when constructing the synthetics. Although the long period features of data and the two corresponding synthetics are similar, as is expected from theoretical arguments (Helmberger and Malone, 1975), the synthetics for subcrustal focal depths match the broadband features of the data much better, with many individual phases aligned.

To invert whole broadband seismograms for source depths and mechanisms, we apply a grid search in the source parameter space (strike, dip, rake, $M_{0}$, depth) to find the global minimum of misfit between the synthetic and observed waveforms (Zhao and Helmberger, 1994). An advantage of the method is that it allows time shifts between various portions of the observations and synthetics, thus relaxing the strong dependence of the inversion on the velocity model and the influence of lateral variation. Uncertainty of the solution can be estimated easily by quantifying the misfit error distribution around the global minimum.

The global minima of the 3 events as a function of depth are shown in Fig. 5. As expected, the waveform misfit errors of all 3 events decrease rapidly as the

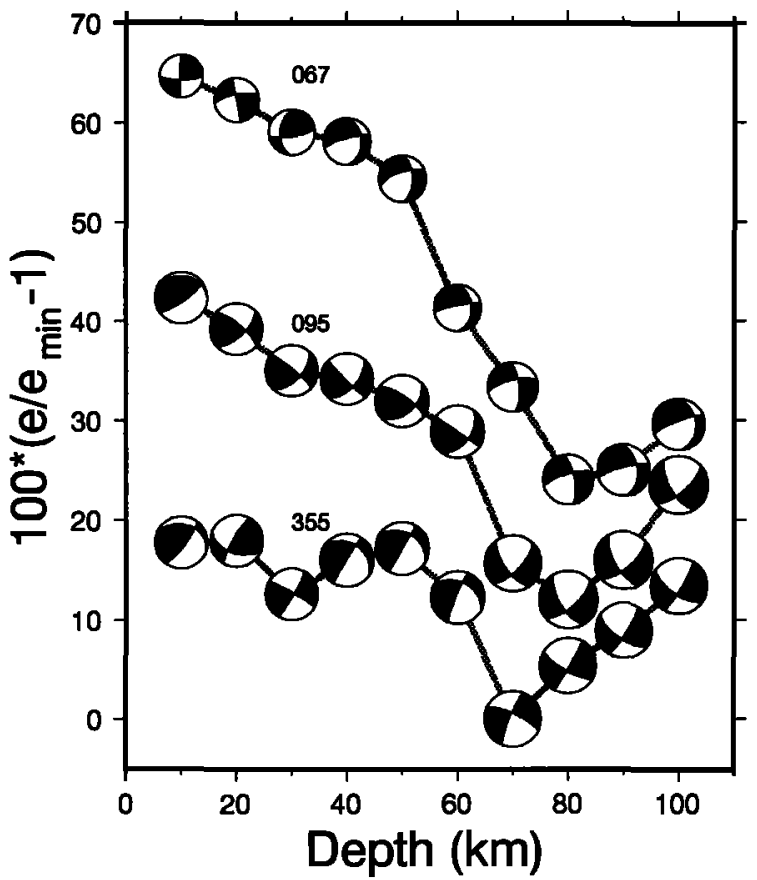

Figure 5. Waveform misfit as function of focal depth. The misfit errors are normalized by the minimum. Curves for Event 095 and 067 are offset for displaying reason.

sources drop below the Moho. The mechanisms show some depth dependence but remain mostly strike-slip. Table 3 lists the inversion results at the best-fit depths and the uncertainties estimated by examining all the solutions with misfit errors within $5 \%$ of the minimum. For all 3 events, the azimuths of the $P$ and $T$ axes are better constrained (within $10^{\circ}$ ), while the plunges are relatively poorly constrained (within $10^{\circ}-20^{\circ}$ ).

In Fig. 1 we have plotted the lower-hemisphere projection of the best fault plane solutions. The source mechanisms of the two events under the HTB display strong strike-slip behavior with some normal faulting. They are quite different from the mechanisms of shallow events in the same area, which show consistent lowangle thrusting along the front of the Himalaya with slip vectors perpendicular to the mountain range (Molnar and Chen, 1983; Baranowski et al., 1984; Ni and Barazangi, 1984; Molnar and Lyon-Caen, 1989). The mechanism of the event near the suture zone is similar to the mechanism of the previous intermediate depth event nearby (Fig. 1), except that it has more strikeslip component. The T-axes are all horizontal in the

Table 3. Focal Depths and Fault Plane Solutions From Waveform Modeling

\begin{tabular}{crccc}
\hline Event & \multicolumn{1}{c}{$P$ axis ${ }^{a}$} & $T_{\text {axis }}{ }^{a}$ & $h(\mathrm{~km})$ & $M_{0}$ \\
\hline 355 & $157 \pm 6 / 6 \pm 20$ & $252 \pm 7 / 3 \pm 15$ & 70 & 1.41 \\
067 & $210 \pm 6 / 27 \pm 11$ & $303 \pm 8 / 3 \pm 11$ & 80 & 0.25 \\
095 & $6 \pm 6 / 31 \pm 11$ & $277 \pm 9 / 3 \pm 14$ & 80 & 2.00 \\
\hline
\end{tabular}

${ }^{a}$ Azimuth/Plunge, all in degrees; $M_{0}$ in $10^{16} \mathrm{Nm}$. 
EW direction and the P-axes are roughly in the NS direction. This is consistent with a regional stress field produced by the indenting of the India continent.

\section{Discussion}

Focal depth determinations based on global network traveltimes have always been difficult because of the trade-off between the depth and origin time (Zhao and Helmberger, 1991). This trade-off can be eliminated by the use of depth phases, $\mathrm{pP}$ and $\mathrm{sP}$, but these phases become difficult to identify for magnitudes below 5 , especially for strike-slip orientations. With broadband records at regional distances, the constraints on focal depths can be substantially improved. In particular, waveform modeling proves very effective in discriminating between crustal and subcrustal events, due to their fundamental waveform differences. Moreover, our success in modeling the broadband waveforms up to $1000 \mathrm{~km}$ distance range with a simple 1D velocity model shows that to the first order the plateau has a relatively simple crustal structure. But we also emphasize that lateral variation does exist. For example, the tangential displacements at stations WNDO, ERDO, and BUDO are delayed about $5 \mathrm{sec}$ relative to the synthetics. These three stations are located in the north-central plateau where a mid-crustal low velocity zone is reported (Brandon and Romanowicz, 1986; Zhy et. al, 1995).

In summary, we have detected 3 intermediate depth earthquakes in the India-Tibet collision zone in a oneyear time window. Taking into account three previous reports, it is reasonable to speculate that there are other unidentified intermediate depth earthquakes with moderate magnitudes in this area. The existence of intermediate depth earthquakes under the Himalaya and Indus Zangbo suture indicates the temperatures of the mantle lithosphere in southern Tibet are relatively low. The small number of these events studied to date limits our ability to explore the details of structure and rheology of the lithospheric mantle, but we believe that with the installation and operation of the permanent CDSN station at Lhasa, more data will be available to shed light on questions about the tectonics in this continentcontinent collision zone.

Acknowledgments. We thank 3 anonymous reviewers, L. Burdick, C. Scrivner, T. Melbourne, and X. Song for their helpful comments on the manuscript. This work has been supported by the Department of Defense as monitored by the Air Force Office of Scientific Research under contract F49620-92-J-0470. Contribution No. 5556, Division of Geological and Planetary Sciences, California Institute of Technology, Pasadena, California.

\section{References}

Baranowski, H., H. Armbruster, L. Seeber and P. Molnar, Focal depths and fault plane solutions of earthquakes and active tectonics of the Himalaya, J. Geophys. Res., 89, 6919-6928, 1984.

Brandon, C., and B. Romanowicz, A 'no-lid' zone in the central Chang-Tang platform of Tibet: Evidence from pure path phase velocity measurement of long period Rayleigh waves, J. Geophys. Res., 91, 6547-6546, 1986.

Chen, W.-P., J.L. Nabelek, T.J. Fitch, and P. Molnar, An intermediate depth earthquake beneath Tibet: Source characteristics of the event of September 14, 1976, J. Geophys. Res., 86, 2863-2876, 1981.

Chen, W.-P., A brief update on the focal depths of intracontinental earthquakes and their correlation with heat flow and tectonic age, Seismo. Res. Lett., 59, 263-272, 1988.

Ekstrom, G., A broadband method of earthquake analysis, Ph.D. Dissertation, 215 pp., Harvard Univ., Combridge, MA, 1987.

Helmberger, D.V. and S.D. Malone, Modeling local earthquakes as shear dislocations in a layered half space, $J$. Geophys. Res., 80, 4881-4888, 1975.

Molnar, P., A review of geophysical constraints on the deep structure of the Tibetan Plateau, The Himalaya and the Karakoram, and their tectonic implications, Phil. Trans. $R$. Soc. Lond., A326, 33-88, 1988.

Molnar, P., and W.-P. Chen, Focal depths and fault plane solutions of earthquakes under the Tibetan Plateau, $J$. Geophys. Res., 88, 1180-1196, 1983.

Molnar, P., and W.-P. Chen, S-P wave travel time residuals and lateral inhomogeneity in the mantle beneath Tibet and the Himalaya, J. Geophys. Res., 89, 6911-6917, 1984.

Molnar, P., and H. Lyon-Caen, Fault plane solutions of earthquakes and active tectonics of the Tibetan Plateau and its margins, Geophys. J. Int., 99, 123-153, 1989.

$\mathrm{Ni}$, J., and M. Barazangi, Seismotectonics of the Himalayan collision zone: geometry of the underthrusting Indian plate beneath the Himalaya, J. Geophys. Res., 89, 11471163, 1984.

Owens, T.J., G.E. Randall, F.T. Wu, and R.S. Zeng, PASSCAL instrument performance during the Tibetan plateau passive seismic experiment, Bull. Seismol. Soc. Am., 89, 1959-1970, 1993.

Randall, G.E., C.J. Ammon, and T.J. Owens, Momenttensor estimation using regional seismograms from portable network deployments, Geophys. Res. Lett., 22, 1665-1668, 1995.

Romanowicz, B., Constraints on the structure of the Tibet Plateau from pure path phase velocities of love and Rayleigh-waves, J. Geophys. Res., 87, 6865-6883, 1982.

Saikia, C.K. and L.J. Burdick, Fine-structure of Pnl waves from explosion, J. Geophys. Res., 96, 14383-14401, 1991.

Zhao, L. and D.V. Helmberger, Geophysical implication from relocation of Tibetan earthquakes - hot lithosphere, Geophys. Res. Lett., 18, 2205-2208, 1991.

Zhao, L. end D.V. Helmberger, Source estimation from broadband regional seismograms, Bull. Seismol. Soc. $A m .$, 84, 91-104, 1994.

Zhu, L., T.J. Owens, and G.E. Randall, Lateral variation in crustal structure of the northern Tibetan Plateau inferred from teleseismic receiver functions, Bull. Seismol. Soc. Am., in press, 1995.

Seismological Laboratory, California Institute of Technology, Pasadena, CA 91125.

(received June 5, 1995; revised October 19, 1995; accepted December 19, 1995.) 